\title{
SIMULATING HYPE CYCLE CURVES WITH MATHEMATICAL FUNCTIONS : SOME EXAMPLES OF HIGH-TECH TRENDS IN JAPAN
}

\author{
Hiroshi Sasaki ${ }^{1}$ \\ ${ }^{1}$ College of Business, Rikkyo University, Tokyo, Japan
}

\begin{abstract}
In this study, a method to simulate Gartner's hype cycle [1] is proposed. A search of the academic literature on this topic provides no clear guidance on how to draw hype cycle curves with mathematical functions. This article explores a new process for simulating the curve as a combination of bell-shaped curves and S-shaped curves, and applies this process to some high-tech innovations in Japan. Trends in technologies such as customer relationship management (CRM), supply chain management (SCM), and cloud computing are analyzed by using a corpus of 4,772 newspaper articles. For these examples, Gompertz functions show better fit than logistic functions. For the combined curve, polynomial functions of degree 9 provide the best fit, with adjusted $R$-square values of more than 0.97 .
\end{abstract}

\section{KEYWORDS}

Hype cycle, High-tech innovation, S-shaped curves, Diffusion of innovations

\section{INTRODUCTION}

Gartner's hype cycle [1] is a popular method for visually showing an ongoing high-tech innovation process. Fenn and Raskino [2] noted that "the hype cycle's particular contribution is in highlighting the challenge of adopting an innovation during the early stages of the innovation's life cycle." Executives and managers check new hype cycle reports as a means of trying to find new technological trends.

This study explores a new approach for simulating hype cycle curves with mathematical functions. This paper is organized as follows. The next section reviews the literature related to the generation of the hype cycle. After this, we propose a three-step process for simulating hype cycle curves and then apply that process to some high-tech innovations, examining trends in areas such as customer relationship management (CRM), supply chain management (SCM), and cloud computing in Japan.

\section{LITERATURE REVIEW}

\subsection{Five key phases of the hype cycle}

Gartner's hype cycle consists of five key phases [1]. The first phase is Innovation trigger (Technology trigger), which begins when an announcement about a technological development drives sudden interest [2]. In "Hype Cycle for Emerging Technologies, 2014" [3], "bio acoustic sensing" appears in the first phase. The second phase, Peak of inflated expectations, begins when

DOI : 10.5121/ijmit.2015.7201 
publicized stories capture the excitement around the innovation and reinforce the need to become a part of it [2][4]. In the same report [3], "data science" is shown entering into the second phase, and the "Internet of Things" is positioned at the top of the peak of expectations, where it displaces the trend on "big data." The third phase, Trough of disillusionment, occurs when impatience for results begins to replace the original excitement about potential value [2]. Fenn and\& Raskino [2] explains that "a number of less favorable stories start to emerge as most companies realize things aren't as easy as they first seemed". In 2014, we see "cloud computing" reaching the bottom of the trough. During the fourth phase, Slope of enlightenment, early adopters overcome the initial hurdles, and understanding grows about where the innovation can be used[2]. Three-dimensional (3D) technologies, such as "Enterprise 3D printing" and "3D scanners," are in this phase. The last phase, Plateau of productivity, begins when growing numbers of organizations feel comfortable with the now greatly reduced levels of risk [2].

Thus, Gartner's hype cycle [1] clarifies the position of each high-tech innovation. However, only those in the Gartner organization can create the hype cycle, and researchers outside of Gartner have no tools to generate it.

\subsection{How to measure technology expectations}

A critical issue for this study is to provide a measure for technology expectations. To do so, we searched for empirical studies that meet the conditions below.

1. Source: The articles available in August 2014 in the Academic Source Premier and Business Source Premier databases of EBSCO Information Services

2. Key word: The phrase "hype cycle" was used for the search.

3. Conditions: The search was restricted to academic journals and periodicals published in English.

As a result, 25 articles were extracted. We extracted 66 additional articles (including 2 duplicates) from the Science Direct database by searching for "Gartner's hype cycle." After eliminating the duplicates and 22 articles from fields other than social sciences, 67 articles remained. These articles were categorized into three types: qualitative analysis (53 articles), quantitative analysis ( 9 articles), and other (5 articles; essays, editor's comments, etc.).

\section{(1) Articles with qualitative analysis}

Figure 1 shows the technologies covered by 53 articles that focused on qualitative analysis. In these studies, researchers try to apply the hype cycle model to education, cloud computing, security, software, and energy and the environment, among other topics. 


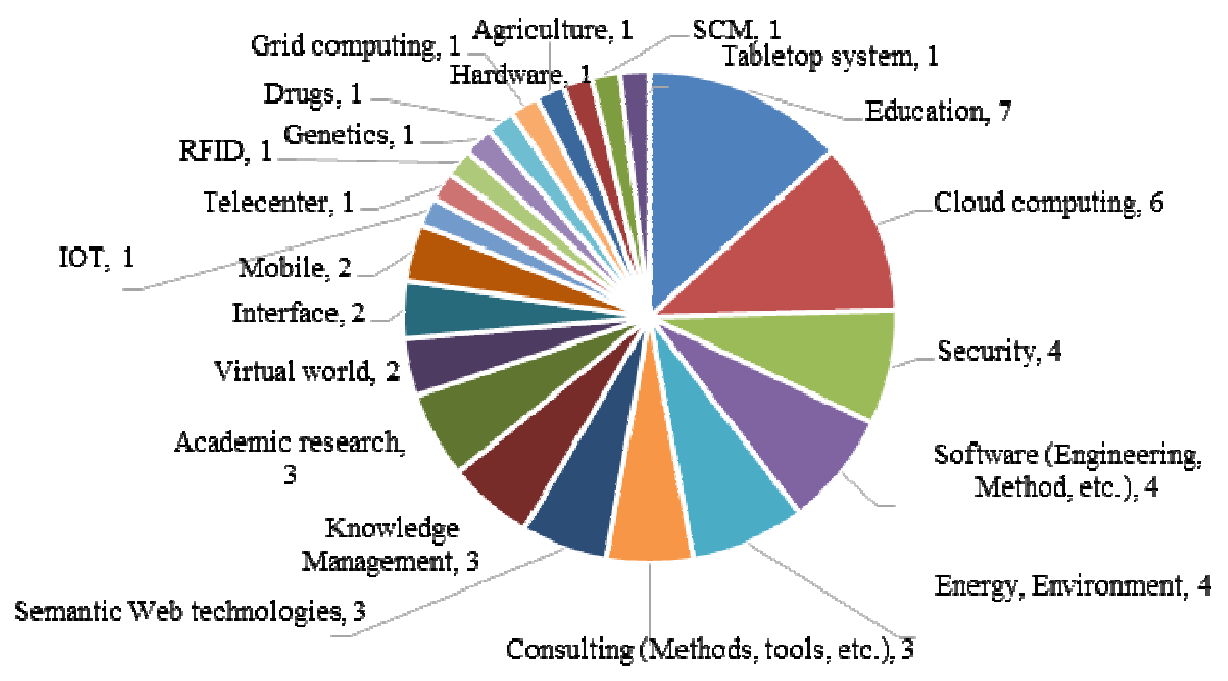

Figure 1. Technologies discussed in 53 papers with qualitative analysis

\section{(2) Articles with quantitative analysis}

Table 1 illustrates the measures and data sources employed in the 9 articles for simulating hype cycle curves[5][6][7][8][9][10][11][12][13]. It is popular in these studies to measure the cycle (technology expectations) from Innovation trigger to Trough of disillusionment by counting the number of items about the technology (news stories, papers, books, and so on); in contrast, patent statistics are commonly used when measuring from Slope of enlightenment to Plateau of productivity.

Table 1. Summary of quantitative measures

\begin{tabular}{|l|l|l|l|}
\hline No & \multicolumn{1}{|c|}{ Authors } & \multicolumn{1}{|c|}{ Subject } & \multicolumn{1}{|c|}{ Method of Measurement } \\
\hline 1 & Gray et al. (2014)[5] & $\begin{array}{l}\text { Accounting-related expert systems } \\
\text { publications }\end{array}$ & $\begin{array}{l}\text { Yearly distribution of expert } \\
\text { systems research }\end{array}$ \\
\hline 2 & Lente et al. (2013)[6] & $\begin{array}{l}\text { Voice over internet protocol (VoIP), } \\
\text { gene therapy, and high-temperature } \\
\text { superconductivity. }\end{array}$ & Number of newspaper articles \\
\hline 3 & Budde et al. (2013)[7] & $\begin{array}{l}\text { Hybrid-electric vehicle (HEV) and } \\
\text { Fuel-cell vehicle (FCV) technology }\end{array}$ & $\begin{array}{l}\text { Number of press releases and } \\
\text { patent statistics }\end{array}$ \\
\hline 4 & Vahid (2012)[8] & Unified Modeling Language (UML) & Number of books on UML \\
\hline 5 & Jun (2012)[9] & Hybrid cars & $\begin{array}{l}\text { Search traffic on Google, news } \\
\text { articles, and patent statistics }\end{array}$ \\
\hline 6 & Konrad (2012)[10] & Stationary fuel cells & Number of newspaper articles \\
\hline 7 & Kim et al. (2012)[11] & Approx. 500 emerging technologies & $\begin{array}{l}\text { Papers and patents } \\
\text { information, Decision tree } \\
\text { model }\end{array}$ \\
\hline 8 & $\begin{array}{l}\text { Ruef\& Markard } \\
\text { (2010)[12] }\end{array}$ & Stationary fuel cells & Number of newspaper articles \\
\hline 9 & Konrad (2006)[13] & $\begin{array}{l}\text { Electronic commerce and interactive } \\
\text { television }\end{array}$ & Number of newspaper articles \\
\hline
\end{tabular}


International Journal of Managing Information Technology (IJMIT) Vol.7, No.2, May 2015

The contents of Table 1 are consistent with the findings of Jun[9], who notes that the number of news stories and patents can well explain consumer behavior along the hype cycle. More importantly, in the same article, Jun divides the hype cycle into two separate curves, and states that a) the first curve is a bell curve representing the initial cycle of enthusiasm and disappointment, and b) the second curve is an S-shaped curve showing how an innovation's performance improves slowly at first and then accelerates steadily before finally yielding diminishing returns [9].

We adopt this idea of treating hype cycle curves as comprising two stages. We call them as "the hype stage" and "the implementation stage".

(A) The hype stage: This stage covers the period from Innovation trigger to Trough of disillusionment. The curve for this stage can be constructed as a bell-shaped curve, with time along one axis and the instantaneous (non-cumulative) number of articles along the other. One popular way to measure this stage is to use the number of items (newspaper articles, academic papers, books) mentioning the technology or the volume of search traffic about the technology as the non-time axis.

(B) The implementation stage: This stage covers Slope of enlightenment and Plateau of productivity. The curves for this stage can be simulated by S-shaped curves with time along one axis and cumulative number of articles along the other. In some of the literature, patent statistics are used for the non-time axis.

\section{A PROCESS FOR SIMULATINGHYPE CYCLE CURVES WITH MATHEMATICAL FUNCTIONS}

To position ongoing high-tech innovations along a hype cycle curve, mathematical functions are needed. This section proposes a three-step process for doing so, with mathematical functions.

\section{(1) Data collection}

Similar to previous studies, this paper uses newspaper articles. After collecting newspaper data for each high-tech innovation, we divide the articles into two stages, (A) the hype stage and (B) the implementation stage, according to the content of the article. The key issue at this point is how to determine which stage should be used for each article. Among the titles of the articles, a substantial number mention either organizational changes or the appointment of managers as innovation proceeds. Such articles state, for example, "Company X appointed Mr. Y as a new SCM leader" or "Company X forms a new SCM division." This type of article indicates that the mentioned company is in the implementation stage. We can partition articles into one of the two stages on the basis of this type of content.

\section{(2) Curve fitting}

There are several cumulative time series that form an S-shaped curve. To seek the best S-shaped curve for each stage, two sigmoid functions (Gompertz and logistic) were examined. It should be noted that, in our previous study [14], we found that Gompertz functions fit better than logistic functions for some IT innovations. The forms of these functions are given by the following.

1.Logistic function: $\mathrm{y}=\mathrm{a} /(1+\mathrm{b} \exp (-k x))$

2.Gompertz function: $\mathrm{y}=a \exp \left(-\exp \left(-k\left(x-x_{c}\right)\right)\right)$ 
These two functions are distinguished by differences in their waveforms. The logistic function provides a curve that is symmetrical around the inflection point; in contrast, the Gompertz function forms a curve that is not symmetrical around the point of inflection. This study applies the two functions to the two stages separately(Figure 2).

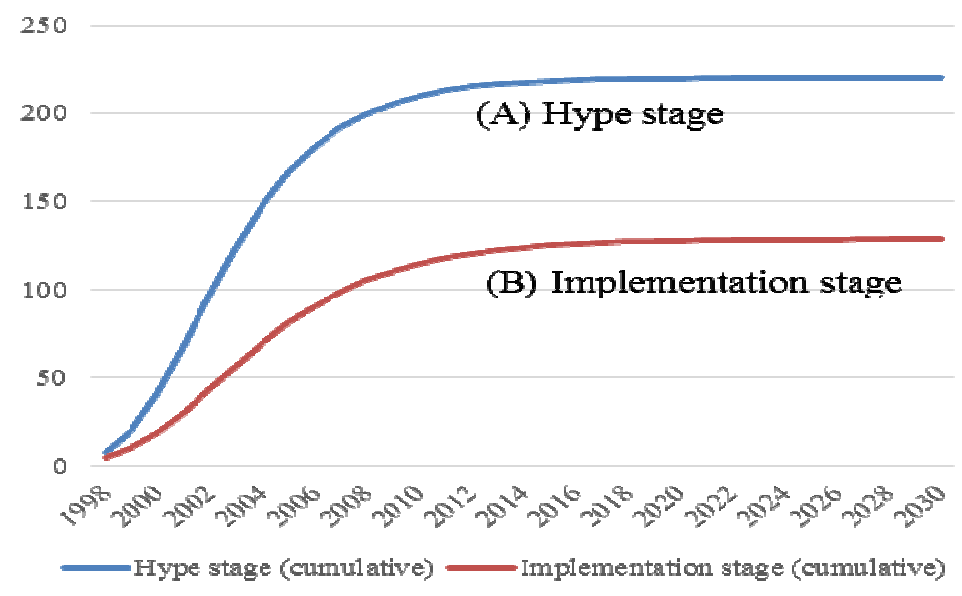

Figure 2. A sample curve fitting

To form a curve for the hype stage, S-shaped curves (formed by using cumulative data) will be transformed to bell-shaped curves that use non-cumulative data. By combining the two curves after data standardization, we obtain an initial hype cycle curve (see the dotted curve in Figure 3).

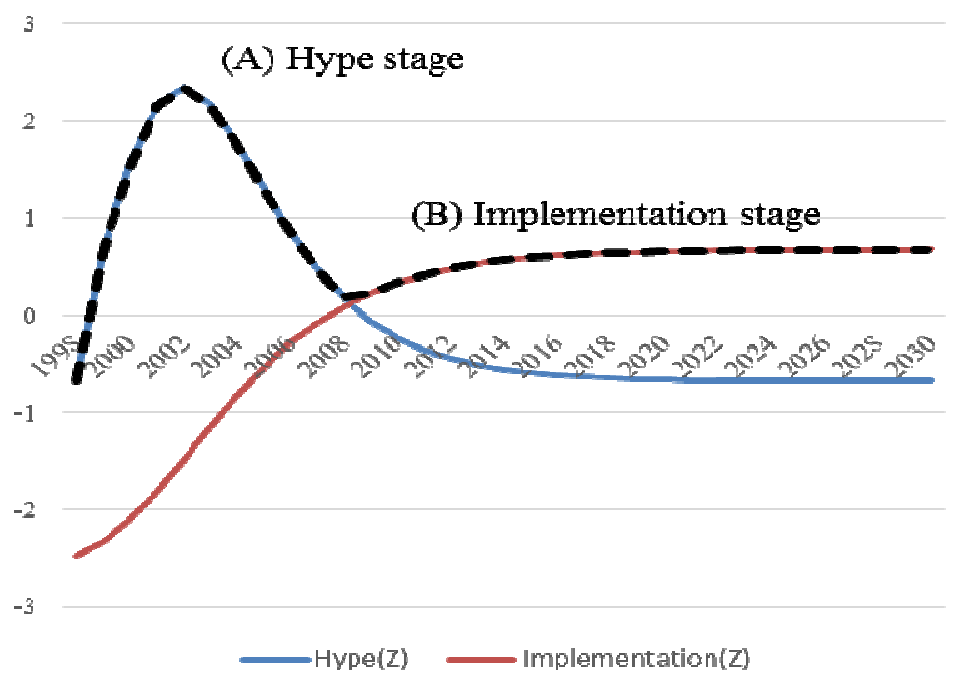

Figure 3. A sample hype cycle curve

\section{(3) Polynomial fitting}

We conduct polynomial fitting to express the dotted curve with mathematical functions. Polynomial functions of degrees 5, 7, and 9 are tested.

1. Polynomial functions of degree $5: \mathrm{y}=$ intercept $+\sum_{i=1}^{5}\left(B_{i} x_{i}\right)$

2. Polynomial functions of degree 7:y $=$ intercept $+\sum_{i=1}^{7}\left(B_{i} x_{i}\right)$

3. Polynomial functions of degree $9: \mathrm{y}=$ intercept $+\sum_{i=1}^{9}\left(B_{i} x_{i}\right)$ 


\section{HYPE CYCLE CURVE SIMULATION FOR HIGH-TECH INNOVATIONS IN JAPAN}

Articles printed in the Nikkei newspaper (Japan's leading economic newspaper) are used as data for simulating hype cycle curves. All articles printed in the Nikkei morning edition from 1990 to the end of March 2014 were searched, and articles containing any of the following terms were selected: SCM, CRM, and cloud computing. From among all articles, 4,772 articles were extracted: 616 articles for CRM; 1,550 for SCM; and 2,606 for cloud computing.

\subsection{CRM}

Figure 4 shows the diffusion process for CRM in Japan. In this figure, the line graph for the hype stage represents the non-cumulative number of articles about CRM, and the line graph for the implementation stage represents the cumulative number of articles on the same topic.

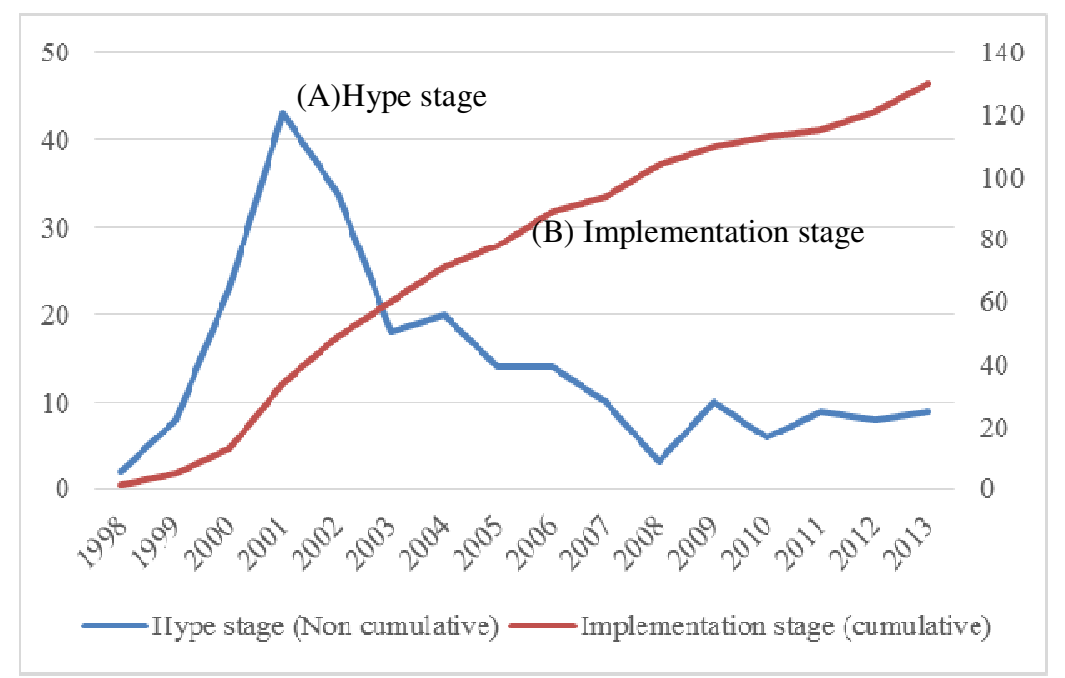

Figure 4. Time series of Nikkei articles about CRM

We fit Gompertz and logistic functions to the two line graphs. As a result, the Gompertz functions showed better fit than the logistic functions for both stages (see Table 2 for the adjusted Rsquared values).

Table 2. S-shaped curve fitting for CRM

\begin{tabular}{|c|c|c|}
\hline Logistic function & Hype stage & Implementation stage \\
\hline Number of points & 16 & 16 \\
\hline Degrees of freedom & 13 & 13 \\
\hline Reduced Chi-squared & 161.88294 & 41.47205 \\
\hline Residual sum of squares & 2104.47818 & 539.13661 \\
\hline Adj. R-squared & 0.97206 & 0.97748 \\
\hline Gompertz function & Hype stage & Implementation stage \\
\hline Number of points & 16 & 16 \\
\hline Degrees of freedom & 13 & 13 \\
\hline Reduced Chi-squared & 74.1598 & 235.6552 \\
\hline Residual sum of squares & 964.0774 & 0.99016 \\
\hline Adj. R-squared & 0.9872 & \\
\hline
\end{tabular}


Table 3 shows the best-fit parameter values for the Gompertz function. After data standardization, the initial hype cycle with a bell-shaped curve for the hype stage and an S-shaped curve for the implementation stage can be obtained (Figure 5).

Table 3. Best-fit parameter values of Gompertz function

\begin{tabular}{|c|c|c|c|}
\hline Best fit parameters & & Value & $\begin{array}{c}\text { Standard } \\
\text { error }\end{array}$ \\
\hline Hype stage & $\mathrm{a}$ & 219.807 & 5.36602 \\
\hline & $\mathrm{xc}$ & 4.43241 & 0.16187 \\
\hline & $\mathrm{k}$ & 0.35532 & 0.03165 \\
\hline Implementation stage & $\mathrm{a}$ & 128.6113 & 3.96502 \\
\hline & $\mathrm{xc}$ & 5.31204 & 0.18904 \\
\hline & $\mathrm{k}$ & 0.28213 & 0.02388 \\
\hline
\end{tabular}

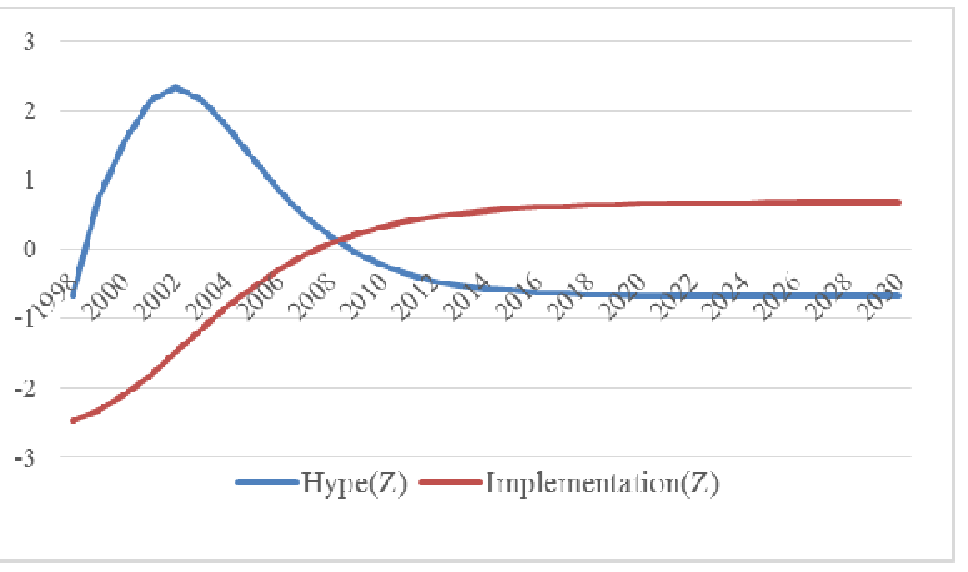

Figure 5.Bell-shaped curve and S-shaped curve for CRM (after data standardization)

Next, we conducted polynomial fitting to seek the best-fit functions. Table 4 summarizes the results. The best-fit function was a polynomial of degree 9 (adjusted R-squared value of 0.99229). By using the parameter values ( $B_{1}$ to $B_{9}$ and the intercept), we can draw a hype cycle curve for CRM (Figure 6; the circle indicates the position of 2014).

Table 4. Polynomial fitting for CRM

\begin{tabular}{|c|c|}
\hline Polynomial,degree5 & \\
\hline Number of points & 33 \\
\hline Degrees of freedom & 27 \\
\hline Residual sum of squares & 1.65385 \\
\hline Adj. R-Squared & 0.83371 \\
\hline Polynomial,degree7 & \\
\hline Number of points & 33 \\
\hline Degrees of freedom & 25 \\
\hline Residual sum of squares & 0.43774 \\
\hline Adj. R-squared & 0.95247 \\
\hline Polynomial,degree9 & \\
\hline Number of points & 33 \\
\hline Degrees of freedom & 23 \\
\hline Residual sum of squares & 0.06536 \\
\hline Adj. R-squared & 0.99229 \\
\hline
\end{tabular}


International Journal of Managing Information Technology (IJMIT) Vol.7, No.2, May 2015

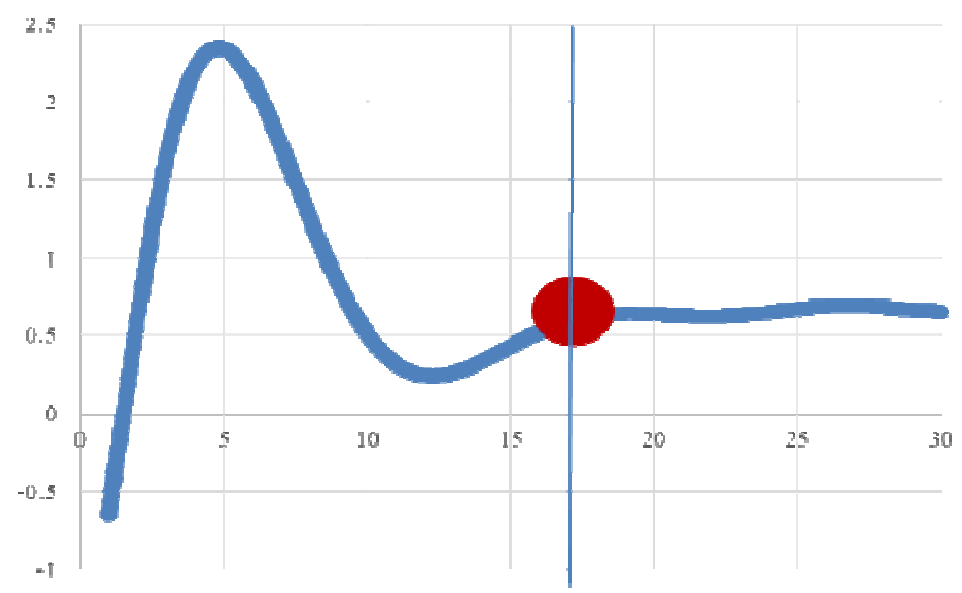

Figure 6. Simulated hype cycle curve for CRM

\subsection{SCM}

Similarly, Figures7, 8, and Table 5 show the process to simulate the hype cycle curve for SCM. We obtain Figure 9 (the best-fit function was a polynomial of degree 9 with Adj. R-squared: 0.99656) as the result of that process.

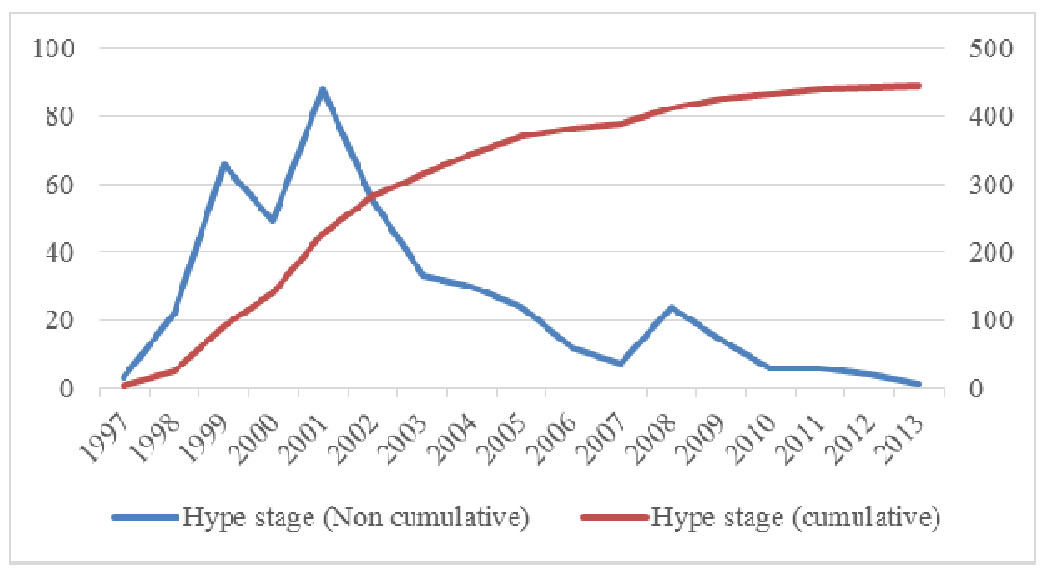

Figure 7. Time series of Nikkei articles about SCM 
International Journal of Managing Information Technology (IJMIT) Vol.7, No.2, May 2015

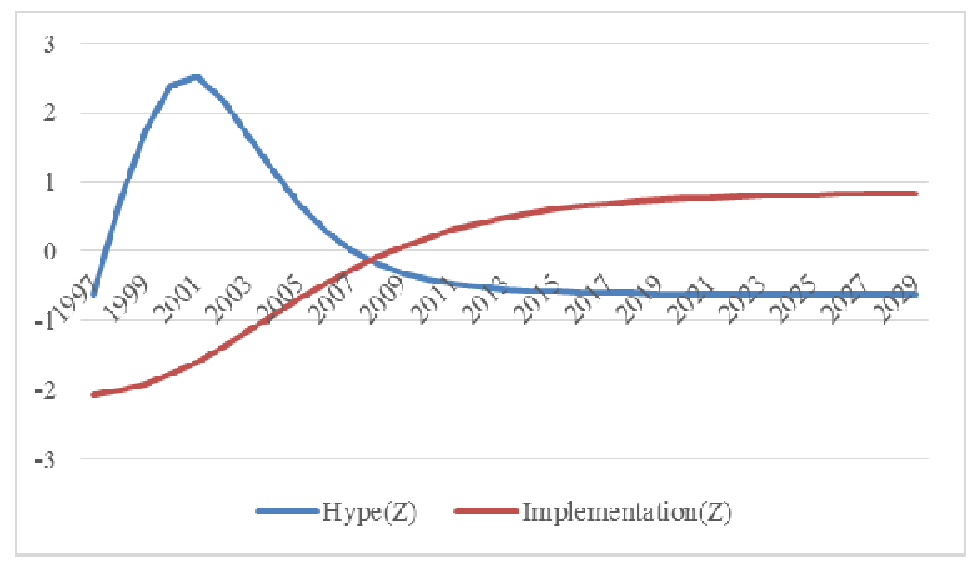

Figure 8. Bell-shaped curve and S-shaped curve for SCM (after data standardization)

Table 5. S-shaped curve fitting for SCM

\begin{tabular}{|l|c|c|}
\hline \multicolumn{1}{|c|}{ Logistic function } & Hype stage & Implementation stage \\
\hline Number of points & 17 & 17 \\
\hline Degrees of freedom & 14 & 14 \\
\hline Reduced Chi-squared & 380.89083 & 117.77175 \\
\hline Residual sum of squares & 5332.47167 & 1648.80457 \\
\hline Adj. R-squared & 0.98341 & 0.98166 \\
\hline
\end{tabular}

\begin{tabular}{|l|c|c|}
\hline \multicolumn{1}{|c|}{ Gompertz function } & Hype stage & Implementation stage \\
\hline Number of points & 17 & 17 \\
\hline Degrees of freedom & 14 & 14 \\
\hline Reduced Chi-squared & 131.17589 & 45.66755 \\
\hline Residual sum of squares & 1836.4625 & 639.34571 \\
\hline Adj. R-squared & 0.99429 & 0.99289 \\
\hline
\end{tabular}

\begin{tabular}{|c|c|}
\hline Polynomial of degree 9 & \\
\hline Number of points & 34 \\
\hline Degrees of freedom & 24 \\
\hline Residual sum of squares & 0.03615 \\
\hline Adj. R-squared & 0.99656 \\
\hline
\end{tabular}

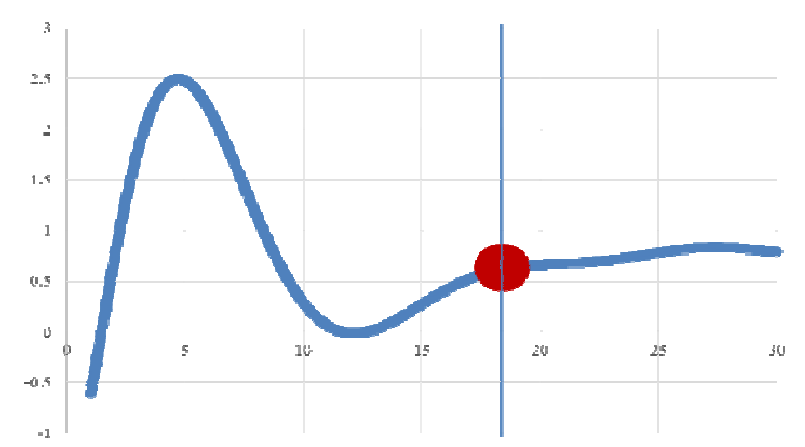

Figure 9. Simulated hype cycle curve for SCM 


\subsection{Cloud computing}

Cloud computing is still in the hype stage and experiencing growth. Figures 10 and11 and Table 6 show the process, and Figure 12 shows the hype cycle curve for cloud computing (the best-fit function was a polynomial of degree 9 with Adj. R-squared: 0.97438), as calculated by the proposed method.

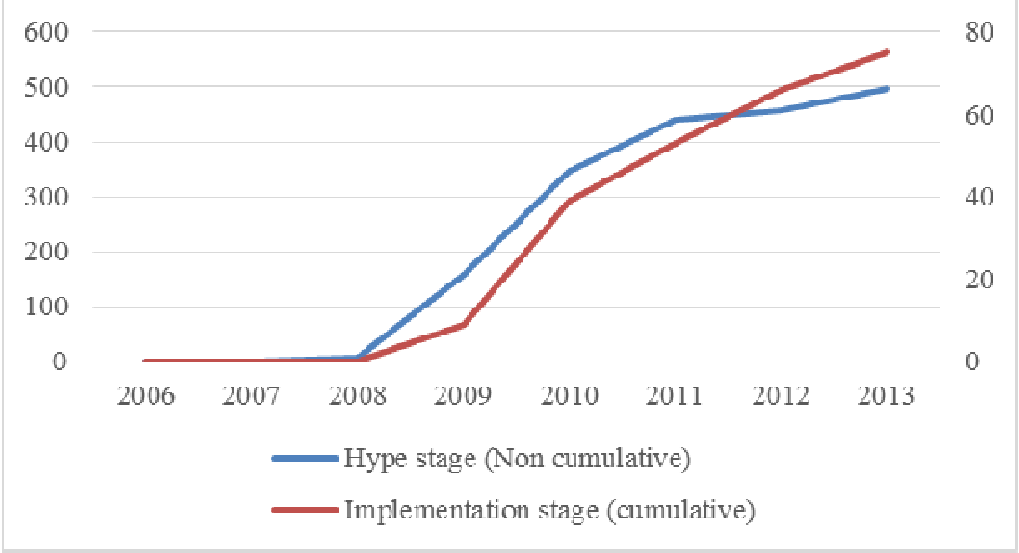

Figure 10. Time series of Nikkei articles about cloud computing

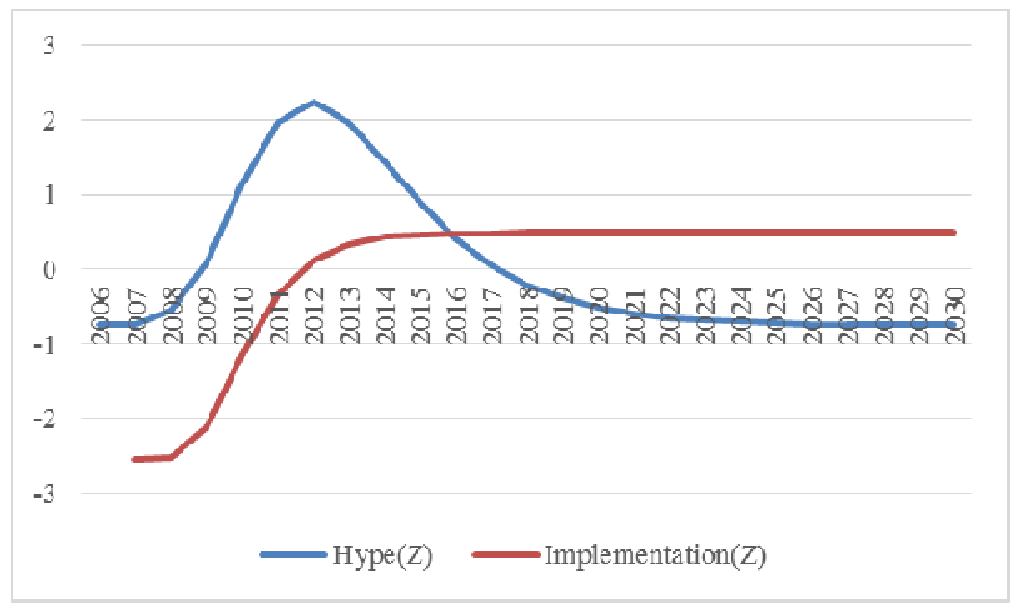

Figure 11. Bell-shaped curve and S-shaped curve for cloud computing (after data standardization)

Table 6. S-shaped curve fitting and polynomial fitting for cloud computing

\begin{tabular}{|c|c|c|}
\hline Logistic function & Hype stage & Implementation stage \\
\hline Number of points & 8 & 6 \\
\hline Degrees of freedom & 5 & 3 \\
\hline Reduced Chi-squared & 2860.65605 & 27.91975 \\
\hline Residual sum of squares & 14303.28026 & 83.75924 \\
\hline Adj. R-squared & 0.99464 & 0.96986 \\
\hline
\end{tabular}

\begin{tabular}{|c|c|c|}
\hline Gompertz function & Hype stage & Implementation stage \\
\hline Number of points & 8 & 6 \\
\hline Degrees of freedom & 5 & 3 \\
\hline
\end{tabular}


International Journal of Managing Information Technology (IJMIT) Vol.7, No.2, May 2015

\begin{tabular}{|c|c|c|}
\hline Reduced Chi-squared & 552.55357 & 11.79637 \\
\hline Residual sum of squares & 2762.76784 & 35.3891 \\
\hline Adj. R-squared & 0.99896 & 0.98726 \\
\hline
\end{tabular}

\begin{tabular}{|c|c|}
\hline Polynomial of degree 9 & \\
\hline Number of points & 25 \\
\hline Degrees of freedom & 15 \\
\hline Residual sum of squares & 0.20605 \\
\hline Adj. R-squared & 0.97438 \\
\hline
\end{tabular}

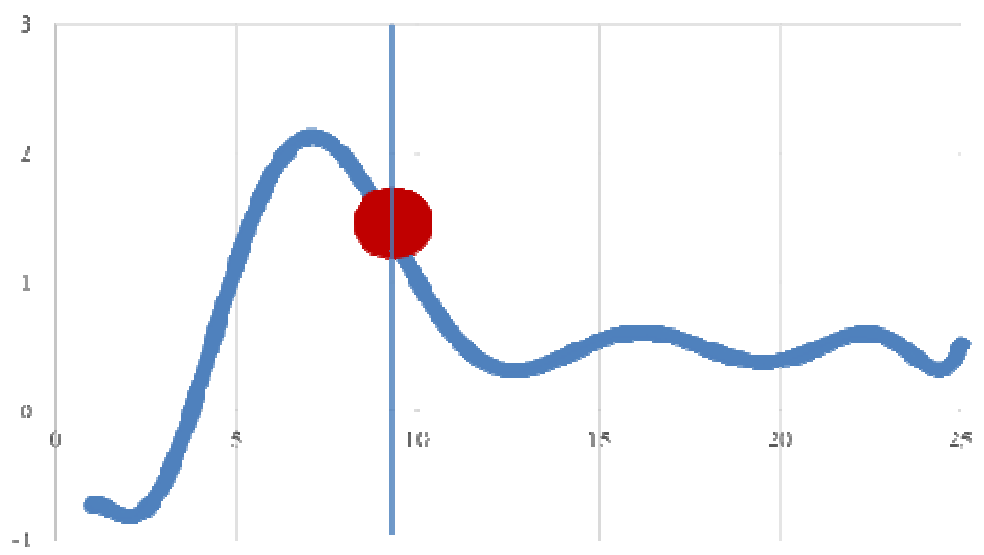

Figure 12. Simulated hype cycle curve for cloud computing

\section{SUMMARY AND CONCLUSIONS}

This study demonstrated a method of simulating Gartner's hype cycle[1] with mathematical functions. By applying polynomial functions, the current position along the curve could be identified. Because of the simplicity and operational ease of this method in comparison with other complex simulation technologies, the proposed method is suggested for use when trying to capture the state of high-tech innovations.

Through the process, this study found some common features among the diffusion patterns of different high-tech innovations. First, our simulation of S-shaped curves indicated that during both the hype stage and the implementation stage Gompertz functions show better fit than logistic functions in all examined high-tech innovations. This result, which agrees with results from our previous study [14], means that the high-tech innovation process is not symmetrical around the point of inflection for both stages. Second, polynomial functions of degree 9 demonstrated the best fit for the combined curve, with adjusted R-squared values of more than 0.99 for CRM,0.99 for SCM, and 0.97 for cloud computing. This means that hype cycle curves can be simulated roughly by polynomial functions.

In conclusion, it is reasonable to claim that this study makes the following contributions: (1) it proposes a process for simulating hype cycle curves, and (2) it shows the mathematical functions that can be used to understand the position along the hype cycle. However, there are two noteworthy limitations to this study. First, when examining newspaper articles, we identified the implementation stage by using the titles (specifically, titles mentioning organizational changes or announcing the appointment of managers were taken as indicating the implementation stage). 
Despite this, these organizational changes are not the only indicators that could be used to confirm the implementation stage. Second, we used only polynomial functions of degrees 5, 7 , and 9. We need to apply polynomials of higher degrees, such as 11, 13, and 15, and examine other functions that to see whether they are more appropriate. Such extensions are left for future study.

\section{REFERENCES}

[1] Gartner,Inc.,(n.d.)“Gartner Hype Cycle”, Retrieved from http://www.gartner.com/technology/research/methodologies/hype-cycle.jsp (21 March, 2015).

[2] Fenn, Jackie. \& Raskino, Mark, (2008) Mastering the Hype Cycle -How to Choose the Right Innovation at the Right Time, Harvard Business Press.

[3] Gartner, Inc., (2014) "Gartner's 2014 Hype Cycle for Emerging Technologies Maps the Journey to Digital Business",Retrieved from http://www.gartner.com/newsroom/id/2819918 (21March, 2015).

[4] Kim,Song-kyoo, (2013) "General framework for management of technology evolution", The Journal of High Technology Management Research, Vol. 24, No. 2, pp130-137.

[5] Gray, Glen. Chiu, Victoria. Liu, Qi. \& Li, Pei, (2014) “The expert systems life cycle in AIS research: What does it mean for future AIS research?", International Journal of Accounting Information Systems, Vol. 15, pp423-451.

[6] Lente, Harro. Spitters, Charlotte. \& Peine, Alexander,(2013)“Comparing technological hype cycles: Towards a theory”, Technological Forecasting and Social Change, Vol. 80, No. 8, pp 1615-1628.

[7] Budde, Björn. Alkemade, Floortje. \&Hekkert, Marko,(2013) "On the relation between communication and innovation activities: A comparison of hybrid electric and fuel cell vehicles", Environmental Innovation and Societal Transitions, Vol.14, March 2015, pp.45-59.

[8] Vahid, Garousi, (2012) "Classification and trend analysis of UML books (1997-2009)", Software \& Systems Modeling. Vol. 11, No. 2, pp273-285.

[9] Jun, Seung-Pyo,(2012)“A comparative study of hype cycles among actors within the socio-technical system: With a focus on the case study of hybrid cars", Technological Forecasting and Social Change, Vol. 79, No. 8, pp1413-1430.

[10] Konrad, Kornelia. Markard, Jochen. Ruef, Annette. \& Truffer, Bernhard, (2012) "Strategic responses to fuel cell hype and disappointment", Technological Forecasting and Social Change, Vol. 79, No. 6, pp1084-1098.

[11] Kim, Jinhyung. Hwang, Myunggwon. Jeong, Do-Heon. \& Jung, Hanmin,(2012) “Technology trends analysis and forecasting application based on decision tree and statistical feature analysis", Expert Systems with Applications, Vol. 39, No.16, pp12618-12625.

[12] Ruef, Annette.\& Markard, Jochen,(2010) "What happens after a hype? How changing expectations affected innovation activities in the case of stationary fuel cells", Technology Analysis \& Strategic Management, Vol. 22, No. 3, pp317-338.

[13] Konrad, Kornelia, (2006)“The social dynamics of expectations: The interaction of collective and actor-specific expectations on electronic commerce and interactive television", Technology Analysis \& Strategic Management, Vol. 18, No. 3/4, pp429-444.

[14] Sasaki, Hiroshi, (2014) "Time lags related to past and current IT innovations in Japan: An analysis of ERP, SCM, CRM, and big data trends", International Journal of Business Analytics, Vol. 1, No. 1, pp29-42. 